Chemotherapy 1977;23(Suppl. 1):302

\title{
Urinary Tract Infections Treated with Fosfomycin
}

\begin{tabular}{|l|l|l|}
\hline R.L. & Landinez & Lagunero \\
\hline M.L. & López & Menéndez \\
\hline
\end{tabular}

Cátedras de Microbiología y Obstetricia, Facultad de Medicina, Valladolid

\section{Summary}

Fosfomycin is a new antibiotic of bactericide action and useful in the treatment of urinary infections. The results described were obtained with its use on 34 patients with acute and subacute urinary infections

as well as another smaller group of 8 cases with chronic bacteriurias. All of the germs isolated in the uroculture of the patients were sensitive to a $30 \mu \mathrm{g}$ fosfomycin disc - two patients with germs which were resistant to treatment

were excluded. There was a $100 \%$ satisfactory result in the patients with acute infections who were treated with fosfomycin orally for 1 week. The 8 chronic bacteriuria patients responded satisfactorily to treatment sometimes using the oral route or a combination of the oral and intramuscular route. There was a patient who had a relapse after 4 weeks treatment but was cured completely after a second treatment when the oral and intramuscular routes were used together. A criterion of cure on patients was only reached when it was proved that the causal germs in the urine had disappeared 4-8 weeks after the end of treatment. 1 This paper was published in Folia clin. int. 24: 3-15 (1974). 